\title{
Sprint interval training on the vertical treadmill improves aerobic and anaerobic running performance
}

\author{
Alastair Ross Jordan ${ }^{1, *}$, David Claxton², Alison Purvis², Andrew Barnes², Mary Fysh² \\ 'School of Sport, York St. John's University, Lord Mayor's Walk, York, United Kingdom \\ ${ }^{2}$ Academy of Sport and Physical Activity, Sheffield Hallam University, Sheffield, United Kingdom
}

The vertical treadmill (VertiRun) is an unresearched mode of exercise where users engage in a "running-like" action whilst body weight is supported by a recumbent bench and overhanging resistance cables are tethered to the user's ankles. The purpose of this study was to determine the effects of training on a VertiRun and any cross-training effect on running performance. Thirty active males (age, $22 \pm 4$ years; stature, $1.79 \pm 0.08 \mathrm{~m}$; body mass, $78.5 \pm 12.6 \mathrm{~kg}$ ) volunteered for this study. Participants' aerobic and anaerobic running performance were determined by incremental maximum rate of oxygen consumption $\left(\mathrm{VO}_{2 \max }\right)$ treadmill test and a maximum anaerobic running test (MART), respectively. Participants were matched and then randomly assigned to either a VertiRun group, 20-m shuttle sprint group or control group. The intervention consisted of 4-6, 30-sec all-out efforts with 4-min recovery between bouts, 3 days a week for 6 weeks. The pre- and postintervention
$\mathrm{VO}_{2 \max }$ and MART were analysed using a mixed repeated measures analysis of variance. MART increased by $4.5 \%$ in the VertiRun group $(P=0.006)$ and $4 \%$ in the sprint group $(P<0.001) . \mathrm{VO}_{2 \max }$ increased by $6.2 \%$ in the VertiRun group $(P=0.009)$ and $5.5 \%$ in the sprint group $(P=0.020)$. The MART and $\mathrm{VO}_{2 \max }$ of the control group were unchanged $(P=0.910$ and $P=0.915$, respectively). These data suggest that the VertiRun could be an effective cross-training mode for running and could supplement training programmes. Also, as VertiRun is a low-impact exercise it might be useful in the physical preparation of athletes returning to sport following lower limb injury.

Keywords: VertiRun, Cross-training, Low impact exercise, Non-weight bearing, Aerobic training, Anaerobic training

\section{INTRODUCTION}

The specificity principle denotes that central and peripheral adaptations are specific to the training stimulus and exercise mode (Millet et al., 2009). In contrast with the specificity principle, training programmes usually incorporate elements of cross-training where the athlete engages with exercise modes that differ from the competition mode, with the intention of improving cardiovascular and musculoskeletal performance (Flynn et al., 1998; Foster et al., 1995). Cross-training for sports that involve large volumes of high speed running often includes partial or nonweight bearing exercise such as cycling, recumbent stepping, antigravity treadmill running and aquatic exercise to reduce the mechanical load on the musculoskeletal system and potentially prevent overuse injuries (Hreljac, 2004; Sobhani et al., 2013). The training stimulus from partial and nonweight bearing exercise differs from overground running due to innate differences in the exercise modes. Despite differences in the mode, cross-training can improve, or at least maintain running performance in untrained to moderately trained athletes (Hass et al., 2001; Joubert et al., 2011; Loy et al., 1994; Millet et al., 2002; Millet al., 2009; Mutton et al., 1993).

The vertical treadmill (VertiRun, Sheffield, United Kingdom) is a new, unresearched low-impact exercise mode that could be a useful cross-training mode for running because users engage in a "running-like" action with body weight supported (Jordan et al., 2017). The VertiRun consists of a vertically hung, non motorised treadmill, an adjustable bench mechanism and overhanging resistance cables (Fig. 1). The body posture and position of the user, with respect to the treadmill belt, can be manipulated by adjust-
${ }^{*}$ Corresponding author: Alastair Ross Jordan (iD https://orcid.org/0000-0002-7669-4753 School of Sport, York St. John's University, Lord Mayor's Walk, York, YO31 7EX, United Kingdom

Tel: +44-1904-876-125, Fax: +44-1904-876-500, E-mail: a.jordan1@yorksj.ac.uk Received: September 27, 2017 / Accepted: January 13, 2018
This is an Open Access article distributed under the terms of the Creative Commons Attribution Non-Commercial License (http://creativecommons.org/licenses/by-nc/4.0/) which permits unrestricted non-commercial use, distribution, and reproduction in any medium, provided the original work is properly cited. 

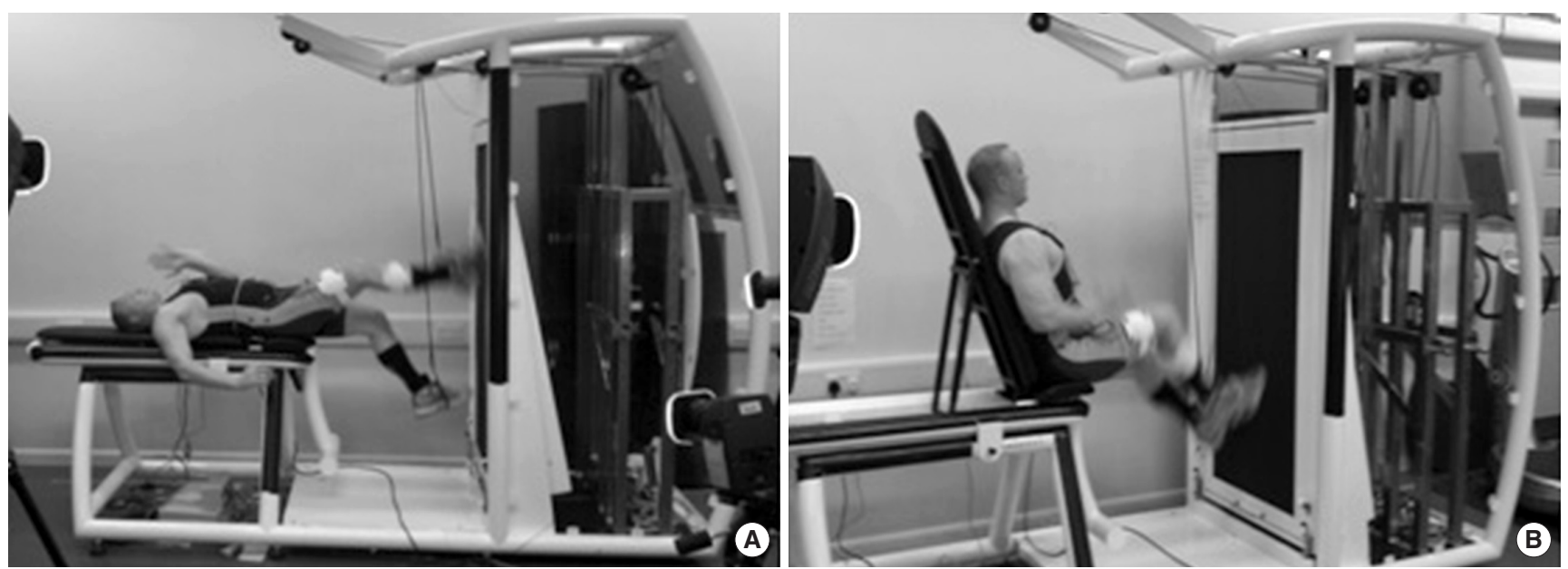

Fig. 1. The VertiRun being used in the supine posture $(A)$ and $70^{\circ}$ posture (B).

ing the bench angle and fore and aft settings. The overhanging cables are tethered to the ankle and offer resistance to the musculature of the posterior chain ( $20 \mathrm{~N}$ on the uptake of tension, up to $70 \mathrm{~N}$ as the leg descends to the lowest point of the treadmill). Therefore, the magnitude of the resistance is dependent on the leg length, leg mass and the lower limb range of motion of the user.

VertiRun exercise appears to be similar in nature to running with the benefit of a resistive component (Jordan et al., 2017) and could be an appropriate cross-training exercise for any athlete for which running is the mode of locomotion. Currently, the VertiRun lacks peer reviewed research as a cross-training exercise and practitioners lack the evidence to support the use of VertiRun in training programmes. Therefore, the purpose of this study was to determine the efficacy of VertiRun training on aerobic and anaerobic running performance.

\section{MATERIALS AND METHODS}

\section{Participants}

After institutional ethics approval, thirty male participants (age, $22 \pm 4$ years; stature, $1.79 \pm 0.08 \mathrm{~m}$; body mass, $78.5 \pm 12.6 \mathrm{~kg}$ ) were informed of the benefits and risks of the investigation prior to providing written consent to participate in the study. All participants were healthy, physically active students and engaged in intermittent sprint-type sports (rugby, soccer, and hockey) 2 to 3 times per week.

\section{Procedure}

One week prior to commencing with the study, all participants undertook familiarisation of the intervention tests and the VertiRun. VertiRun familiarisation sessions consisted of $2 \times 30 \mathrm{~min}$ of submaximal exercise with very brief maximal efforts ( $3-5$ reps, $20 \mathrm{sec}$ ). Following familiarisation, aerobic and anaerobic running performance of the participants was assessed by an incremental maximal aerobic running capacity $\left(\mathrm{VO}_{2 \max }\right)$ test and maximal anaerobic running test (MART), respectively. The $\mathrm{VO}_{2 \max }$ and MART tests were separated by 48-hr rest. Each testing session began with a self-selected 'light' warm up, rated 9 on Borg's rating of perceived exertion (RPE) scale (Borg, 1998) on a conventional motorised treadmill with a $1^{\circ}$ incline (Saturn, HP Cosmos, Nussdorf Traunstein, Germany) for 5 min, followed by 5 min of self-selected dynamic stretches.

\section{Maximal aerobic running capacity}

The $\mathrm{VO}_{2 \text { max }}$ was determined by breath-by-breath pulmonary gas analysis (CPX Ultima, MedGraphics Corp., St. Paul, MN, USA) during an incremental test on a conventional motorised treadmill with $1^{\circ}$ incline throughout. The initial speed was $9 \mathrm{~km} /$ $\mathrm{hr}$ and increased by $1 \mathrm{~km} / \mathrm{hr}$ every minute until volitional fatigue. Pulmonary gas analysis was recorded throughout the test, heart rate and RPE were recorded $15 \mathrm{sec}$ before the end of every minute and at volitional fatigue. Blood lactate concentration (BLa) was measured immediately after the $\mathrm{VO}_{2 \max }$ test via the finger prick method and analysed (YSI1500 Sport Lactate Analyser, YSI Inc., Yellow Springs, OH, USA). The $\mathrm{VO}_{2}$ data was subject to $30 \mathrm{sec}$ averaging and was plotted against exercise intensity. The highest interval indicated $\mathrm{VO}_{2 \max }$ and was verified by a plateau in the $\mathrm{VO}_{2}$-intensity relationship, a respiratory exchange ratio of at least 1.15 and an RPE of 18-20. 


\section{Maximal anaerobic running test}

The MART is a maximal exhaustive test consisting of several 20-sec bouts of running on a treadmill at a $10.5 \%$ gradient with 100-sec recovery between bouts. The MART started at a speed of $14.3 \mathrm{~km} / \mathrm{hr}$ and increased every bout by $1.2 \mathrm{~km} / \mathrm{hr}$ until volitional fatigue (Maxwell and Nimmo, 1996; Rusko et al., 1993). BLa measurement was taken immediately after the MART. Maximal anaerobic running performance was calculated using the $\mathrm{O}_{2}$ equivalents formula for treadmill running $\left(\mathrm{VO}_{2}=3.5+12 \mathrm{v}+54\right.$ $\mathrm{gv})$, where ' $\mathrm{v}$ ' is the treadmill speed $(\mathrm{m} / \mathrm{sec})$ and ' $\mathrm{g}$ ' is the treadmill gradient expressed as a fraction (American College of Sports Medicine, 2005). The treadmill speed of the last completed $20 \mathrm{sec}$ was used in the calculation. An incomplete bout incurred an additional $1 \mathrm{~mL} / \mathrm{kg} / \mathrm{min}$ to the anaerobic performance score if at least $10 \mathrm{sec}$ was completed and another $1 \mathrm{~mL} / \mathrm{kg} / \mathrm{min}$ for every $2 \mathrm{sec}$ after (Maxwell and Nimmo, 1996; Rusko et al., 1993).

\section{Training intervention}

After preintervention testing, participants were matched on their anaerobic performance and then randomly assigned to either a VertiRun group ( $n=10)$, overground sprint group $(n=10)$, or control group $(n=10)$. The VertiRun and overground sprint groups undertook the same sprint interval training (SIT) intervention, only the exercise mode differed. The overground sprint group performed sprints $20-\mathrm{m}$ sprint shuttles in a sports hall. The 6-week intervention consisted of 4-6, 30-sec efforts separated by 4.5 min of low intensity active recovery (RPE 9), 3 times per week. The number of repetitions increased from four during week 1-2, 5 during weeks 3-4 and 6 during weeks 5-6 (Burgomaster et al., 2008; Whyte et al., 2010). The adherence of participants with the intervention was recorded. Postintervention MART and $\mathrm{VO}_{2 \max }$ tests were completed within 1 week of completing the intervention. All participants, including the control group, were asked to continue with their normal activities and dietary habits during the intervention.

\section{Data analysis}

The pre- and postintervention MART and $\mathrm{VO}_{2 \max }$ scores were analysed using a mixed repeated measures analysis of variance (ANOVA) with Bonferroni pairwise comparisons and Cohen $d$ effect sizes (ES). Independent $t$-tests were used to assess for differences in preintervention MART and $\mathrm{VO}_{2 \max }$ between groups and adherence of groups to the intervention. Statistical significance was set at $P \leq 0.05$. All statistical analyses were conducted using IBM SPSS Statistics ver. 23.0 (IBM Co., Armonk, NY, USA).

\section{RESULTS}

\section{Preintervention measures}

The preintervention participant characteristics of the VertiRun, overground sprint, and control groups are shown in Table 1. Prior to the intervention, independent $t$-tests found no difference in the anaerobic or aerobic running performance between the groups as measured by MART $(P=0.995)$ and incremental $\mathrm{VO}_{2 \max }$ treadmill test $(P=0.991)$, respectively.

\section{Adherence to SIT intervention}

The VertiRun group completed $93 \% \pm 7 \%$ and the overground sprint group completed $92 \% \pm 9 \%$ of the total intervention. Independent $t$-tests found no difference in adherence to the intervention between intervention groups $(P=0.918)$.

Table 1. Participant characteristics of the VertiRun, overground sprint, and control group

\begin{tabular}{lccc}
\hline Characteristic & VertiRun & Sprint & Control \\
\hline Age $(\mathrm{yr})$ & $22 \pm 4$ & $22 \pm 3$ & $21 \pm 4$ \\
Stature $(\mathrm{m})$ & $1.82 \pm 0.07$ & $1.79 \pm 0.07$ & $1.80 \pm 0.10$ \\
Body mass $(\mathrm{kg})$ & $82.1 \pm 5.2$ & $73.2 \pm 16.3$ & $80.2 \pm 13.1$ \\
\hline
\end{tabular}

Values are presented as mean \pm standard deviation.

Table 2. The pre- and postintervention MART and $\mathrm{VO}_{2 \max }$ of each group and subsequent peak (BLa)

\begin{tabular}{|c|c|c|c|c|c|c|}
\hline \multirow{2}{*}{ Variable } & \multicolumn{2}{|c|}{ VertiRun } & \multicolumn{2}{|c|}{ Sprint } & \multicolumn{2}{|c|}{ Control } \\
\hline & Pre & Post & Pre & Post & Pre & Post \\
\hline MART (mL/kg/min) & $105.2 \pm 8.6^{*}$ & $109.9 \pm 8.6$ & $104.8 \pm 9.3^{*}$ & $108.9 \pm 9.2$ & $104.9 \pm 7.1$ & $104.9 \pm 6.5$ \\
\hline MART (BLa) (mmol/L) & $10.4 \pm 1.8$ & $10.0 \pm 1.3$ & $10.0 \pm 1.2$ & $10.4 \pm 0.9$ & $10.5 \pm 1.7$ & $10.7 \pm 2.03$ \\
\hline $\mathrm{VO}_{2 \max }(\mathrm{mL} / \mathrm{kg} / \mathrm{min})$ & $46.8 \pm 5.4^{*}$ & $49.6 \pm 4.7$ & $47.1 \pm 4.5^{*}$ & $49.7 \pm 5.3$ & $46.9 \pm 4.9$ & $46.2 \pm 3.9$ \\
\hline $\mathrm{VO}_{2 \max }(\mathrm{BLa})(\mathrm{mmol} / \mathrm{L})$ & $7.2 \pm 1.5$ & $7.4 \pm 1.2$ & $7.3 \pm 1.5$ & $7.2 \pm 0.9$ & $8.1 \pm 1.3$ & $9.2 \pm 2.2$ \\
\hline
\end{tabular}

Values are presented as mean \pm standard deviation.

MART, maximum anaerobic running test; $\mathrm{VO}_{2 \max }$, maximum aerobic running power; BLa, blood lactate concentration.

*Indicates difference between pre- and postintervention $(P<0.05)$. 


\section{Pre- and postintervention measures}

As shown in Table 2, repeated-measures ANOVA identified a difference in MART $(F[1,27]=32.458, P<0.001)$ and $\mathrm{VO}_{2 \max }$ $(F[1,27]=16.233, P<0.001)$ following the intervention. Group $\mathrm{x}$ time interactions were also detected in MART $(F[2,27]=16.351$, $P<0.001)$ and $\mathrm{VO}_{2 \max }(F[2,27]=4.891, P=0.015)$. Bonferroni post hoc tests identified an increase in MART of $4.5 \%$ in the VertiRun group $P=0.006, \mathrm{ES}=0.55), 4 \%$ in the overground sprint group $(P<0.001, \mathrm{ES}=0.45)$ and no change in the control group $(P=0.910$, $\mathrm{ES}=0.00)$. The $\mathrm{VO}_{2 \max }$ increased by $6.2 \%$ in the VertiRun group $(P=0.009, \mathrm{ES}=0.56), 5.5 \%$ in the overground sprint group $(P=0.020, \mathrm{ES}=0.40)$ and no change in the control group $(P=0.915$, $\mathrm{ES}=0.143)$. The increases in MART and $\mathrm{VO}_{2 \max }$ were similar between VertiRun and overground sprint group $(P=0.647$ and $P=0.358$, respectively). Peak BLa after the MART and $\mathrm{VO}_{2 \max }$ did not change following the intervention $(P=0.761$ and $P=0.391$, respectively).

\section{DISCUSSION}

The aim of this study was to identify the effects of a 6-week SIT programme performed on the VertiRun on aerobic and anaerobic running ability. These results were contextualised by comparison with overground sprint training and a control group. The key findings of this study were that VertiRun exercise increased the anaerobic running performance by $4.5 \%$ (MART), and increased aerobic performance $\left(\mathrm{VO}_{2 \max }\right)$ by $6.2 \%$ with moderate ES. These VertiRun performance improvements were matched by the overground running SIT group, whereas the control group performance was unchanged. Similar increases in running $\mathrm{VO}_{2 \max }$ and MART in both intervention groups suggests that the VertiRun could be an effective cross-training mode and could supplement training for overground running without detriment to running performance.

The key findings of this study concur with previous evidence that there is a degree of transference of physiological adaptations from partial weight bearing and nonweight bearing training exercise to overground running performance (Loy et al., 1994; Millet et al., 2002; Mutton et al., 1993). Direct comparison with previous cross-training literature is difficult because of differences in the exercise modes, frequency, duration, intensity, training status of the participants, and the aerobic nature of the intervention. Previous research regarding the SIT intervention used in this study has also reported improvements in aerobic and anaerobic cycling performance. For example, anaerobic performance, as measured by Wingate anaerobic cycle ergometer test, increased by
5.4\% (Burgomaster et al., 2006) and 8\% (Whyte et al., 2010) following SIT. Under the specificity principle, improvements in anaerobic performance were to be expected since the SIT programme consisted of repeated high intensity, anaerobic bouts and exhaustive exercise. When compared with the $6 \%$ increase in VO${ }_{2 \max }$ in this study, similar improvements of $6.8 \%$ (Burgomaster et al., 2008) and 9.6\% (Bayati et al., 2011) have also been reported following the cycle ergometer SIT programme. Despite the anaerobic nature of the exercise periods, aerobic adaptations, and improvements were expected because there was a significant demand on the cardiovascular system to support a high aerobic contribution during the rest periods to replenish intramuscular Adenosine Triphosphate and Phosphocreatine in preparation for the next sprint (Burgomaster et al., 2008; Gibala et al., 2006). Literature on SIT cycle training has identified specific physiological adaptations that could underpin the performance improvements for example a 26\%-50\% increase in resting muscle glycogen after just two weeks of SIT training (Burgomaster et al., 2005; Gibala et al., 2006), increased enzymatic activity (cytochrome c oxidase, citrate synthase, pyruvate dehydrogenase, phosphorylase, and 3-hydroxyacyl Coenzyme A dehydrogenase), increased lipid oxidation to reserve higher order substrates (Burgomaster et al., 2005; Burgomaster et al., 2006; Burgomaster et al., 2008; Gibala et al., 2006), increased $\mathrm{H}^{+}$buffering capacity (Burgomaster et al., 2006; Gibala et al., 2006), increase in proportion and cross sectional area of type II muscle fibres, increased neurotransmitters and subsequent increased motor unit activation and the delaying of neurological fatigue during maximal exercise (Ortenblad et al., 2000). In the research on SIT cycling training, the test mode was specific to the training mode (i.e., cycle exercise) and did not consider the transferability of the physiological adaptations from one exercise mode to another. Whether any of these specific physiological adaptations were responsible for the aerobic and anaerobic improvements following VertiRun and overground sprint training is unclear and requires further research.

A characteristic of the VertiRun is the resistance bands that are tethered to the ankle. Loy et al. (1995) suggested that effective cross-training modes recruit large muscle mass and could condition musculature that was previously untrained. The VertiRun recruits large muscle mass of the lower limbs, especially musculature of the posterior chain (Jordan et al., 2017). In untrained and moderately fit participants, simply training large muscle masses during nonspecific exercise could provide a sufficient training stimulus for central and peripheral adaptations to improve overground running performance, however elite athletes require 
mode-specific training to develop their physical capacities further (Loy et al., 1995; Ruby et al., 1996; Stangier et al., 2016). The targeting of the posterior chain musculature during VertiRun exercise could condition the posterior chain, which is generally under conditioned relative to anterior musculature of the lower limb (Ahmad et al., 2006; Askling et al., 2003). Posterior thigh muscle strength and a rebalancing of the posterior:anterior thigh muscle strength ratio are believed to be significant contributors to running performance (Askling et al., 2003; Bračič et al., 2011; Chumanov et al., 2011) improves running economy (Sundby and Gorelick, 2014) and has been implemented in preventing multiple lower-limb injuries such as hamstring strains and anterior cruciate ligament ruptures (Ahmad et al., 2006; Rosene et al., 2001). The conditioning of previously poorly conditioned musculature could reduce the deleterious effects of metabolic acidosis and delay the fatigue of other prominent musculature recruited during overground running (Burgomaster et al., 2006; Foster et al., 1995). In this study, MART and $\mathrm{VO}_{2 \max }$ increased in both VertiRun and overground sprint groups without increases in the peak BLa which could be indicative of the musculature sharing the metabolic demand as a result of the SIT intervention.

In cross-training, superior gains in performance have been found when the exercise mode is similar to the test mode (Loy et al., 1995; Tanaka, 1994). The users of the VertiRun undertake a running-like action which is similar to the kinematics and neuromuscular recruitment patterns of overground running (Jordan et al., 2017) and could have facilitated the transfer of adaptations to overground running. The VertiRun is a nonweight bearing exercise mode and therefore athletes could use the VertiRun to increase their training load without the gravity-induced mechanical loading of the lower limbs and risk of overuse injuries that are associated with overground running (Hreljac, 2004; Sobhani et al., 2013). The nonweight bearing nature of VertiRun training, coupled with the training effects identified in this study, suggests that the VertiRun might be also useful in the rehabilitation of lower limb injuries where excessive loading of injured limbs is undesirable. Intense programmes such as SIT might not be appropriate for early rehabilitation stages, however it could be useful in the latter stages to facilitate the physical preparation of athletes returning to sport following a lower limb injury by enhancing aerobic and anaerobic running performance.

Previous studies on cross-training have matched submaximal training loads between the nonmode specific and mode specific training to ensure that changes in performance are due to the mode and not the load of the training stimulus (Loy et al., 1994;
Millet et al., 2002; Mutton et al., 1993; Ruby et al., 1996; Wagner et al., 2013). In contrast, the intervention in this study consisted of repeated bouts of maximal intensity VertiRun exercise, rather than continuous submaximal exercise, partly due to difficulties in quantifying and subsequently matching the training load between VeritRun exercise and overground sprint training. Differences in the training load and metabolic demands probably existed due to the nature of the exercise modes and posture-related differences between the exercise modes. The sprint group had to support their own body weight, however the metabolic load might have been limited by the relatively low metabolic cost of deceleration phases that are not compensated by the demands of reacceleration in the changing direction of shuttle running (Hader et al., 2016). In contrast, VertiRun exercise is nonweight bearing, however resistance bands tethered to the ankles provided resistance to the musculature of the posterior chain and the 30-sec maximal bouts were uninterrupted by changes in direction. Matching training loads based on speed or internal measures such as heart rate and $\mathrm{VO}_{2}$ would not be valid due to differences in the nature of the exercise modes, anaerobic nature of the training intervention, and posture-related differences in the cardiorespiratory system (Billinger et al., 2008; Grönkvist et al., 2002; Jones and Dean, 2004; Prisk et al., 2007; Takahashi et al., 2000) between the recumbent posture of the VertiRun and upright posture of the overground sprint group. Consequently, the training loads between the overground sprint and VeritRun group were not matched stringently and could only be matched on time and that participant efforts were maximal. Although the training load was difficult to quantify in this study, the participants on the VertiRun were able to exercise intensely enough to overload bodily systems and attained changes in running performance to the same degree as mode-specific (overground sprint) training.

In conclusion, 6 weeks of SIT on the VertiRun improved aerobic and anaerobic running performance. The magnitude of the aerobic and anaerobic improvements was comparable to mode-specific training and suggests that the VertiRun could be an effective cross-training mode for any athlete training to improve running performance. The VertiRun is not intended to replace overground run training because of the beneficial mode-specific adaptations (Loy et al., 1994), however coaches and athletes could supplement their training programmes and benefit from certain characteristics of VertiRun exercise. VertiRun offers a low-impact exercise where athletes could increase their training load to overload bodily systems and attain running specific adaptations without the mechanical loading of lower limbs. Therefore, 
the subsequent risk of overuse injuries that are common in running-based training (Hreljac, 2004; Sobhani et al., 2013) could be reduced. The VertiRun could also be used to break the monotony of prolonged running training and enhance adherence to a training programme. Furthermore, the nature of VertiRun exercise might enhance other aspects of physical performance that might not be attainable from running training alone, for example the conditioning of undertrained musculature including the posterior chain. Although the training stimulus could not be quantified and the specific physiological adaptations could not be identified, athletes are able to exercise intensely and achieve a sufficient training stimulus for transferrable adaptations for overground running performance.

This study provides a basis for further research on the VertiRun as a cross-training mode. Further research is imperative to provide coaches and athletes with information on the implications of using the VertiRun as a cross-training mode on running and athletic performance. Therefore, future research should focus on identifying the specific physiological adaptations to VertiRun training, including adaptations to submaximal VertiRun training interventions, the transference of physiological adaptations to performance in sporting contexts and the use of the submaximal VertiRun exercise in the early stages of rehabilitation to maintain fitness and facilitate the return to sport.

\section{CONFLICT OF INTEREST}

No potential conflict of interest relevant to this article was reported.

\section{REFERENCES}

Ahmad CS, Clark AM, Heilmann N, Schoeb JS, Gardner TR, Levine WN. Effect of gender and maturity on quadriceps-to-hamstring strength ratio and anterior cruciate ligament laxity. Am J Sports Med 2006;34: 370-374.

American College of Sports Medicine. ACSM's guidelines for exercise testing and prescription. 7th ed. Baltimore (MD): Lippincott Williams \& Wilkins; 2005.

Askling C, Karlsson J, Thorstensson A. Hamstring injury occurrence in elite soccer players after preseason strength training with eccentric overload. Scand J Med Sci Sports 2003;13:244-250.

Bayati M, Farzad B, Gharakhanlou R, Agha-Alinejad H. A practical model of low-volume high-intensity interval training induces performance and metabolic adaptations that resemble 'all-out' sprint interval train- ing. J Sports Sci Med 2011;10:571-576.

Billinger SA, Loudon JK, Gajewski BJ. Validity of a total body recumbent stepper exercise test to assess cardiorespiratory fitness. J Strength Cond Res 2008;22:1556-1562.

Borg, G. Borg's perceived exertion and pain scales. Champaign (IL): Human Kinetics; 1998.

Bračič M, Hadžič V, Čoh M, Derviševič E. Relationship between time to peak torque of hamstrings and sprint running performance. Isokinet Exerc Sci 2011;19:281-286.

Burgomaster KA, Heigenhauser GJ, Gibala MJ. Effect of short-term sprint interval training on human skeletal muscle carbohydrate metabolism during exercise and time-trial performance. J Appl Physiol (1985) 2006;100:2041-2047.

Burgomaster KA, Howarth KR, Phillips SM, Rakobowchuk M, Macdonald MJ, McGee SL, Gibala MJ. Similar metabolic adaptations during exercise after low volume sprint interval and traditional endurance training in humans. J Physiol 2008;586:151-160.

Burgomaster KA, Hughes SC, Heigenhauser GJ, Bradwell SN, Gibala MJ. Six sessions of sprint interval training increases muscle oxidative potential and cycle endurance capacity in humans. J Appl Physiol (1985) 2005;98:1985-1990.

Chumanov ES, Heiderscheit BC, Thelen DG. Hamstring musculotendon dynamics during stance and swing phases of high-speed running. Med Sci Sports Exerc 2011;43:525-532.

Flynn MG, Carroll KK, Hall HL, Bushman BA, Brolinson PG, Weideman $\mathrm{CA}$. Cross training: indices of training stress and performance. Med Sci Sports Exerc 1998;30:294-300.

Foster C, Hector LL, Welsh R, Schrager M, Green MA, Snyder AC. Effects of specific versus cross-training on running performance. Eur J Appl Physiol Occup Physiol 1995;70:367-372.

Gibala MJ, Little JP, van Essen M, Wilkin GP, Burgomaster KA, Safdar A, Raha S, Tarnopolsky MA. Short-term sprint interval versus traditional endurance training: similar initial adaptations in human skeletal muscle and exercise performance. J Physiol 2006;575(Pt 3):901-911.

Grönkvist M, Bergsten E, Gustafsson PM. Effects of body posture and tidal volume on inter- and intraregional ventilation distribution in healthy men. J Appl Physiol (1985) 2002;92:634-642.

Hader K, Mendez-Villanueva A, Palazzi D, Ahmaidi S, Buchheit M. Metabolic power requirement of change of direction speed in young soccer players: not all is what it seems. PLoS One 2016;11:e0149839.

Hass CJ, Garzarella L, de Hoyos DV, Connaughton DP, Pollock ML. Concurrent improvements in cardiorespiratory and muscle fitness in response to total body recumbent stepping in humans. Eur J Appl Physiol 2001;85:157-163.

Hreljac A. Impact and overuse injuries in runners. Med Sci Sports Exerc 
2004;36:845-849.

Jones AY, Dean E. Body position change and its effect on hemodynamic and metabolic status. Heart Lung 2004;33:281-290.

Jordan AR, Barnes A, Claxton D, Purvis A, Fysh M. Kinematics and neuromuscular recruitment during vertical treadmill exercise. J Exerc Rehabil 2017;13:307-314.

Joubert D, Oden GL, Estes BC. The effects of ellipical cross training on $\mathrm{VO}_{2 \max }$ in recently trained runners. Int J Exerc Sci 2011;4:4-12.

Loy SF, Hoffmann JJ, Holland GJ. Benefits and practical use of cross-training in sports. Sports Med 1995;19:1-8.

Loy SF, Shapiro BI, Hoffmann JJ, Holland GJ, Thompson DL, Vincent WJ, Shaw $S$. Effect of running versus cycle training on cycle ergometer, treadmill, and running performance. Sports Med Train Rehabil 1994; 5:7-15.

Maxwell NS, Nimmo MA. Anaerobic capacity: a maximal anaerobic running test versus the maximal accumulated oxygen deficit. Can J Appl Physiol 1996;21:35-47.

Millet GP, Candau RB, Barbier B, Busso T, Rouillon JD, Chatard JC. Modelling the transfers of training effects on performance in elite triathletes. Int J Sports Med 2002;23:55-63.

Millet GP, Vleck VE, Bentley DJ. Physiological differences between cycling and running: lessons from triathletes. Sports Med 2009;39:179206.

Mutton DL, Loy SF, Rogers DM, Holland GJ, Vincent WJ, Heng M. Effect of run vs combined cycle/run training on $\mathrm{VO} 2 \mathrm{max}$ and running performance. Med Sci Sports Exerc 1993;25:1393-1397.

Ortenblad N, Lunde PK, Levin K, Andersen JL, Pedersen PK. Enhanced sarcoplasmic reticulum $\mathrm{Ca}^{2+}$ release following intermittent sprint training. Am J Physiol Regul Integr Comp Physiol 2000;279:R152-160.

Prisk GK, Yamada K, Henderson AC, Arai TJ, Levin DL, Buxton RB, Hopkins SR. Pulmonary perfusion in the prone and supine postures in the normal human lung. J Appl Physiol (1985) 2007;103:883-894.

Rosene JM, Fogarty TD, Mahaffey BL. Isokinetic hamstrings:quadriceps ratios in intercollegiate athletes. J Athl Train 2001;36:378-383.

Ruby B, Robergs R, Leadbetter G, Mermier C, Chick T, Stark D. Crosstraining between cycling and running in untrained females. J Sports Med Phys Fitness 1996;36:246-254.

Rusko H, Nummela A, Mero A. A new method for the evaluation of anaerobic running power in athletes. Eur J Appl Physiol Occup Physiol 1993;66:97-101.

Sobhani S, Dekker R, Postema K, Dijkstra PU. Epidemiology of ankle and foot overuse injuries in sports: a systematic review. Scand J Med Sci Sports 2013;23:669-686.

Stangier C, Abel T, Mierau J, Hollmann W, Strüder HK. Effects of cycling versus running training on sprint and endurance capacity in inline speed skating. J Sports Sci Med 2016;15:41-49.

Sundby $\mathrm{OH}$, Gorelick ML. Relationship between functional hamstring: quadriceps ratios and running economy in highly trained and recreational female runners. J Strength Cond Res 2014;28:2214-2227.

Takahashi T, Okada A, Saitoh T, Hayano J, Miyamoto Y. Difference in human cardiovascular response between upright and supine recovery from upright cycle exercise. Eur J Appl Physiol 2000;81:233-239.

Tanaka H. Effects of cross-training. Transfer of training effects on VO2max between cycling, running and swimming. Sports Med 1994;18:330339.

Wagner DR, Heath EM, Smith AW. Effect of independent cycle crank training on running economy and $\mathrm{VO}_{2}$ max in distance runners. J Exerc Physiol 2013;16:1-9.

Whyte LJ, Gill JM, Cathcart AJ. Effect of 2 weeks of sprint interval training on health-related outcomes in sedentary overweight/obese men. Metabolism 2010;59:1421-1428. 